\title{
Erratum to: Prediction of tautomer ratios by embedded-cluster integral equation theory
}

\author{
Stefan M. Kast · Jochen Heil · Stefan Güssregen • \\ K. Friedemann Schmidt
}

Published online: 5 May 2010

(C) Springer Science+Business Media B.V. 2010

\section{Erratum to: J Comput Aided Mol Des \\ DOI 10.1007/s10822-010-9340-x}

Owing to an error in the last stages of production, after the authors had seen and corrected the proofs, reference [4] still contained a placeholder instead of the correct citation. Ref. [4] should read:

[4] Geballe MT, Skillman AG, Nicholls A, Guthre JP, Taylor PJ (2010) J Comp Aided Mol Design 24 doi 10.1007/s10822-010-9350-8

The online version of the original article can be found under doi: 10.1007/s10822-010-9340-x.

S. M. Kast $(\bowtie) \cdot$ J. Heil

Theoretische Physikalische Chemie, Technische Universität Dortmund, Otto-Hahn-Str. 6, 44227 Dortmund, Germany

e-mail: kast@keychem.de

S. M. Kast - J. Heil

Eduard-Zintl-Institut für Anorganische und Physikalische Chemie, Technische Universität Darmstadt, Petersenstr. 20, 64287 Darmstadt, Germany

S. Güssregen · K. F. Schmidt

Sanofi-Aventis Deutschland GmbH, R\&D CAS Drug Design FFM, Industriepark Hoechst, 65926 Frankfurt am Main,

Germany 